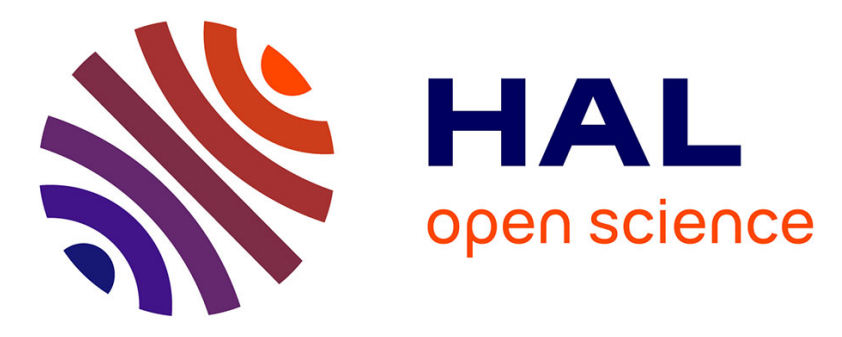

\title{
Drug development in oncology assisted by noninvasive optical imaging.
}

Lucie Sancey, Sandrine Dufort, Véronique Josserand, Michelle Keramidas, Christian A. Righini, Claire Rome, Anne-Charlotte Faure, Stéphanie Foillard, Stéphane G. Roux, Didier Boturyn, et al.

\section{To cite this version:}

Lucie Sancey, Sandrine Dufort, Véronique Josserand, Michelle Keramidas, Christian A. Righini, et al.. Drug development in oncology assisted by noninvasive optical imaging.. International Journal of Pharmaceutics, 2009, 379 (2), pp.309-16. 10.1016/j.ijpharm.2009.05.034 . inserm-00390608

\section{HAL Id: inserm-00390608 https://www.hal.inserm.fr/inserm-00390608}

Submitted on 2 Jun 2009

HAL is a multi-disciplinary open access archive for the deposit and dissemination of scientific research documents, whether they are published or not. The documents may come from teaching and research institutions in France or abroad, or from public or private research centers.
L'archive ouverte pluridisciplinaire HAL, est destinée au dépôt et à la diffusion de documents scientifiques de niveau recherche, publiés ou non, émanant des établissements d'enseignement et de recherche français ou étrangers, des laboratoires publics ou privés. 


\section{Drug development in oncology assisted by noninvasive optical imaging.}

Sancey L. 1-2ł, Dufort S. 1-2-3ł, Josserand V. 1-2, Keramidas M. 1-2, Righini C. 1-2, Rome C. 1-2, Faure A-C. 4, Foillard S. 2-5, Roux S. 4, Boturyn D. 2-5, Tillement O. 4, Koenig A. 6, Boutet J. 6, Rizo P. 6, Dumy P.2-5, Coll JL.1-2*

t These authors contributed equally to this work.

1 CRI-INSERM U823, Cibles diagnostiques ou thérapeutiques et vectorisation de drogues dans les cellules tumorales, Institut Albert Bonniot, BP 170, 38042 Grenoble cedex 9, France 2 Université Joseph Fourier, BP 53, 38041 Grenoble cedex 9, France

3 UF Cancérologie Biologique et Biothérapie, pôle de biologie et pathologie, CHU de Grenoble, BP 217, 38043 Grenoble cedex 9, France

${ }_{4}$ CNRS-UMR 5620, Laboratoire de Physico-Chimie des Matériaux Luminescents, Université Claude Bernard Lyon I, 69622 Villeurbanne cedex, France

5 CNRS, UMR-5250, Département de Chimie Moléculaire, BP 53, 38041 Grenoble cedex 9, France

6 CEA, Laboratoire d'Electronique de Technologie de l'Information, MINATEC, 17 rue des Martyrs, 38054 Grenoble, Cedex 9, France

Correspondance to: Dr Coll Jean-Luc

INSERM U823, Equipe 5

Institut Albert Bonniot, BP 170

38042 Grenoble cedex 9, France

Phone: 33 [0]4 76549553 / Fax: 33 [0]4 76549413

E-mail: Jean-Luc.Coll@ujf-grenoble.fr

Keywords: Drug delivery, optical imaging, tumor targeting. 
Abstract

Early and accurate detection of tumors, like the development of targeted treatments, is a major field of research in oncology. The generation of specific vectors, capable of transporting a drug or a contrast agent to the primary tumor site as well as to the remote (micro-) metastasis would be an asset for early diagnosis and cancer therapy. Our goal was to develop new treatments based on the use of tumor-targeted delivery of large biomolecules (DNA, siRNA, peptides, or nanoparticles), able to induce apoptosis while dodging the specific mechanisms developed by tumor cells to resist this programmed cell death. Nonetheless, the insufficient effectiveness of the vectorization systems is still a crucial issue. In this context, we generated new targeting vectors for drug and biomolecules delivery and developed several optical imaging systems for the follow-up and evaluation of these vectorization systems in live mice. Based on our recent work, we present a brief overview of how noninvasive optical imaging in small animals can accelerate the development of targeted therapeutics in oncology. 


\section{Introduction}

Cancer is a major public health problem. It is the leading cause of death in the world, before cardiovascular diseases. Significant progress has been made in the last decade, but the improvement of diagnosis, with early and accurate detection of tumors, as well as the development of innovative targeted therapies continue to be researched intensely (Cho et al., 2008; Clift et al., 2008; Owens and Peppas, 2006; Pierce et al., 2008).

The generation of specific vectors, capable of addressing a toxic drug and/or a contrast agent to the primary tumor site and remote metastases would therefore be a fundamental asset for early diagnosis and cancer therapy. In collaboration with chemists and physicists, we developed targeted delivery vectors as well as optical imaging systems for tracking them once they have been injected in tumor-bearing mice.

Optical imaging was chosen among the different imaging methods currently available because optics can be applied to a wide range of applications (from cells to animals) as well as to humans (Anandasabapathy, 2008; Tromberg et al., 2005). Indeed, optical imaging is a noninvasive method that can be used to follow the molecules in real time at good spatial (the nanometer to millimeter range) and temporal resolution (microseconds to a few minutes), with high sensitivity (the femto- to picomolar range), and from the whole-body to the subcellular scale (Kumar and Richards-Kortum, 2006).

However, the use of molecular imaging, especially fluorescence imaging in live animal models is limited by the poor transmission of visible light through biological tissues and by the autofluorescence of the tissues because of the presence of natural fluorophores. However, longer wavelengths can be used in a near-infrared (NIR) optical window (650-900 nm). In this spectrum, the problems caused by absorption and autofluorescence are reduced, but 
others are amplified because of the diffusion and scattering of these photons in biological tissues (Ripoll et al., 2005). In addition, the recent description of increasing amounts of organic or inorganic NIR fluorochromes has also contributed to the development of optical imaging methods for the investigation of deep tissues (Weissleder, 2001; Weissleder and Ntziachristos, 2003). This type of fluorochrome can be used for labeling molecules of interest and will significantly accelerate the preclinical study of various kinds of therapeutic, diagnostic, or ultimately theranostic tools (multifunctional nano-carriers with both functions). Optics can also be used to detect subtle spectral variations in biological tissues and thus will help discriminate between normal and pathologic tissues. For example, diffuse NIR imaging was applied for the detection of tumors and the biological evaluation of the response to neoadjuvant chemotherapy in patients with breast cancer (Tromberg et al, 2005). The aim of this article is to illustrate how different optical fluorescence imaging systems can be used to improve the study of macromolecules from the cellular to the small animal scales. This will be exemplified for two kinds of drug carriers: targeted peptides and nanoparticles, visualized with several homemade $2 \mathrm{D}$ and $3 \mathrm{D}$ optical imaging systems. The target peptide we developed, called RAFT(c[-RGDfK-])4 (RAFT-RGD), is a 10- $\AA$ large cyclic peptide able to target the transmembrane protein integrin $\square_{\mathrm{v}} \square_{3}$. This protein is overexpressed on neoformed endothelial cells, such as those forming the tumor blood vessels, where it plays a role in cellular adhesion, proliferation, and migration (Rupp et al., 2004; Stupack and Cheresh, 2002). Furthermore, integrin $\square \mathrm{v} \square 3$ is also frequently overexpressed on several tumor cells themselves, as observed in lung cancers (Chen et al., 2005; Sato et al., 2001), melanomas (Gehlsen et al., 1992; Seftor et al., 1992), brain tumors (Gladson and Cheresh, 1991) and breast cancers (Rolli et al., 2003). Coupled to an optical or nuclear imaging agent, RAFT-RGD can detect metastatic tumors engrafted in mice (Ahmadi et al., 
2008; Garanger et al., 2007; Garanger et al., 2005; Jin et al., 2007; Jin et al., 2006; Sancey et al., 2007) and deliver a toxic (KLAKLAK)2 (KLA) peptide (Foillard et al., 2008). We will illustrate the interest of functional imaging using optics to follow the subcellular release of these peptides.

We have also been involved in the development of various multifunctional nanoparticles (NPs). NPs are very well suited for imaging and/or therapy because of their small size, which is sufficiently large, however, to allow the multiplexing and fine-tuning of several biological functions in a single object. Extensive studies focused on liposomes or polymeric particles have demonstrated how modifying the surface of the particles by adding shielding polymers such as polyethylene glycol (PEG) improve their pharmacodynamic properties (Alexis et al., 2008; Lukyanov and Torchilin, 2004; Owens and Peppas, 2006). The derivatization by PEG chains limits the uptake of the particles by Kupfer cells, macrophages, or B cells and their opsonization by various blood proteins (Alexis et al., 2008, Clift et al., 2008). In this study, we will also illustrate the advantage of using optical systems to rapidly evaluate such modifications.

\section{Material and methods}

\subsection{RGD-Peptides Synthesis and Fluorescent Labeling}

Compounds were synthetized according to previously reported procedures (Boturyn et al., 2004; Foillard et al., 2008): the chemical structures are presented in Fig. 1. Briefly, RAFT is a cyclic decapeptide (c [-Lys(Boc)-Lys(Alloc)-Lys(Boc)-Pro-Gly-Lys(Boc)-Lys(Alloc)Lys(Boc)-Pro-Gly-]) with two orthogonally addressable domains pointing to either side of the cyclopeptide backbone. On the upper side, four copies of the c[-RGDfK-] peptide were 
grafted via an oxime bond (R1-O-N=C-R2) for recognition of the integrin $\square \mathrm{v} \square$ 3. On the other side of the RAFT, a peptidic sequence (KLAKLAK)2-NH2 (KLA) was grafted via a disulfide bridge and a short linker on the lysine chain (c [-KKKPGKAKPG-]) (Garanger et al., 2005). From both parts of this disulfide bridge, a quencher (QSH21 $\left.{ }_{\circledR}\right)$ or a Cy3 mono-NHS (Nhydroxysuccinimide) ester was added on the first cysteine and a Cy5 mono-NHS-ester (all from Amersham Biosciences, Uppsala, Sweden) was added on the second cysteine, as described in Fig. 1. As a negative control probe, RAFT(c[-R $\beta$ ADfK-])4 (RAFT-RAD) was also synthesized in a similar way.

\subsection{Nanoparticles}

The nanoparticles (diameter $\square 15 \mathrm{~nm}$ ) were as described previously (Bridot et al., 2007). They are made up of a metallic heart (Gadolinium oxide) embedded in a polysiloxane shell (Fig. 2). This shell, containing fluorescent dyes (Cy5, Amersham Biosciences) for imaging, is coated with polyethylene-glycol chains (PEG) to optimize their in vivo biodistribution. PEG can be functionalized with biological ligands to target tumor cells (Bridot et al., 2007).

\subsection{Cell Lines and Culture Conditions}

HEK293( $\square 3$ ), stable transfectants of human $\square 3$ from the human embryonic kidney cell line (kindly provided by J-F. Gourvest, Aventis, France), were cultured as described in Jin et al. (2007) in DMEM supplemented with 1\% glutamine, 10\% fetal bovine serum (FBS), 50 units/ml penicillin, $50 \square \mathrm{g} / \mathrm{ml}$ streptomycin, and $700 \square \mathrm{g} / \mathrm{ml}$ Geneticin (G418 sulfate, Gibco, Paisley, UK). IGROV-1, human ovarian carcinoma cells, TS/A-pc, mice mammary carcinoma cells, and TS/A-pc-pGL3 subclone were cultured in RPMI 1640 supplemented with 1\% glutamine, 10\% fetal bovine serum (FBS), $25 \mathrm{nM} \square$-mercaptoethanol, 50 units/ml penicillin, 
and $50 \square \mathrm{g} / \mathrm{ml}$ streptomycin. Stable transfections of TS/A-pc (pGL3) cells were performed using Jet-PEI (Polyplus-transfection, Illkirch, France) with a 4:1 ratio of pCMV-luc and pcDNA3 plasmids, followed by G418 (Invitrogen, Cergy Pontoise, France) selection and cloning of positive cells. All cell lines were cultured at $37^{\circ} \mathrm{C}$ in a humidified $95 \%$ air $/ 5 \%$ $\mathrm{CO}_{2}$ atmosphere. All the cells used here are integrin $\square \mathrm{v} \square$ 3-positive (Jin et al., 2007; Jin et al., 2006; Sancey et al., 2007).

\subsection{FRET experiment}

HEK293( $\square$ 3) cells were grown as described. Fresh warm DMEM without red phenol (Invitrogen, Cergy Pontoise, France) was added to the cells previously stained with $5 \square \mathrm{M}$ Hoechst (Sigma Aldrich, St Quentin Fallavier, France) for 10 minutes. Then, $1 \square \mathrm{M}$ of RAFTRGD-X1 was added to the medium. Confocal microscopy was performed on the Axiovert 200 LSM510 LNO Meta microscope (Carl Zeiss, Jena, Germany) using a 40x water immersion objective. The FRET signal was obtained after excitation at $543 \mathrm{~nm}$ and recovered at 651-716 nm. The Cy3 and Cy5 spectral bleed-through were subtracted from the FRET images.

\subsection{Colocalization studies}

Cells were cultured in four-well Lab-Tek I chambered coverglass (Thermo Fisher, Illkirch, France) in the appropriate medium and kept at $37^{\circ} \mathrm{C}$. The medium was removed and RAFTRGD$\mathrm{X} 2$ was added at $2 \square \mathrm{M}$ for $1 \mathrm{~h}$ in DMEM without FBS and red phenol. Then, $100 \mathrm{nM}$ mito-tracker red (M7512, Invitrogen, Cergy Pontoise, France) was added to the cell medium for 10 minutes together with $5 \square \mathrm{M}$ Hoechst. Cells were carefully rinsed and the medium was replaced for several hours. The cells were observed through confocal microscopy as previously described at $37^{\circ} \mathrm{C}, 5 \% \mathrm{CO}_{2}$. Confocal slices were 0.5 or $1 \square \mathrm{m}$ deep. Images (8-bit 
color) were treated with ImageJ software $1.37 \mathrm{v}(\mathrm{NIH}$, Bethesda, MD, USA).

\subsection{In vivo fluorescence imaging}

\subsubsection{Fluorescence Reflectance Imaging (2D-FRI)}

Female NMRI nude mice (6-8 weeks old, Janvier, Le Genest-Saint-Isle, France) were injected subcutaneously with human HEK293( $\square 3)$ cells $\left(2^{\circ}-107\right.$ cells per mouse). After tumor growth ( $\square 6$ weeks), anesthetized mice (isoflurane/oxygen $3.5 / 4 \%$ for induction and $1.5 / 2 \%$ thereafter, CSP, Cournon, France) were injected intravenously with $200 \square \mathrm{L}$ of nanoparticle suspension (50 $\square \mathrm{M}$ of dye). Depending on the fluorescent dye used, mice were illuminated by 633- or 660-nm light-emitting diodes equipped with interference filters. Fluorescence images as well as black and white pictures were acquired by a back-thinned $\mathrm{CCD}$ camera at $-80^{\circ} \mathrm{C}$ (ORCAII-BT-512G, Hamamatsu, Massy, France) (Jin et a1., 2007; Jin et a1., 2006; Josserand et al., 2007) fit with a colored glass long-pass RG 665 filter (Melles Griot, Voisins Le Bretonneaux, France) or the high-pass RG 9 filter (Schott, Clichy, France). At the end of the experiment, mice were euthanized to quantify the biodistribution in the different organs.

\subsubsection{Fluorescence tomography with fDOT 3D imaging system}

Female NMRI nude mice (6-8 weeks old, Janvier) were injected with 5.10s TS/A-pc-pGL3 cells, intraperitoneally. After tumor growth ( $\square 7$ days), anesthetized mice were injected intravenously with RAFT-RGD-Alexa700 (200 $\square 1$ at $50 \square$ M of dye). Three hours after injection, the anesthetized mouse was put in the dark chamber and was lightly constrained by a glass plate. The imaging setup consists of a laser source $(690 \mathrm{~nm}, 26 \mathrm{~mW}$, Powertechnology, St Nom La Bretche, France) and a CCD camera (ORCA ER, Hamamatsu) fit with a colored glass high-pass RG 9 filter (Schott). The 3D map of fluorescence in the mice was computed by means of an ART-based reconstruction algorithm described 
previously (Herve et al., 2007). After the tomographic acquisition, a FRI as well as a black and white picture were acquired (Koenig et al., 2008; Da Silva et al., 2007).

\subsubsection{Bioluminescence Imaging}

Five minutes after luciferin (Promega, Charbonnières, France) intraperitoneal injection (150 $\mu \mathrm{g} / \mathrm{g}$ ), the mice were anesthetized and bioluminescence images as well as black and white pictures were acquired using a back-thinned $\mathrm{CCD}$ camera at $-80^{\circ} \mathrm{C}$ (ORCAII-BT-512G, Hamamatsu).

\subsubsection{Fluobeam}

The mice bearing TS/A-pc subcutaneous tumor were injected twice intradermically, close to the tumor with $5+5 \square \mathrm{L}$ of nanoparticles (500 $\square \mathrm{M}$ of dye). Mice were imaged with the Fluobeam (Fluoptics, Grenoble, France) $15 \mathrm{~min}, 1 \mathrm{~h}$ and $3 \mathrm{~h}$ after injection. The optical system consists of a 690-nm laser and a pixelfly camera fitted with a high-pass RG 9 filter (Schott).

\section{Results}

\subsection{Optical imaging of drug internalization}

In our previous work, we studied the in vivo optical imaging of RAFT-RGD-Cy5-SS-Q in nude mice bearing subcutaneous tumors (Jin et al., 2007). Because of the presence of a quencher, no fluorescence can be detected $(0.5 \pm 0.1 \%$ of the quantum yield efficiency as compared with the similar molecule without a quencher). This molecule is therefore nearly completely devoid of background fluorescence before the disulfide bridge is disrupted. This provides an excellent SNR (signal-to-noise ratio), which is a major asset in microscopy as well as in whole-body imaging. After intravenous administration of $10 \mathrm{nmol}$ of RAFT-RGDCy5- 
SS-Q, good tumor contrasts were observed from 3 to $24 \mathrm{~h}$ after injection (see supplementary data $\mathrm{S} 1$ ). The kidneys were also visualized. Tumor samples obtained at $3 \mathrm{~h}$ showed that RAFT-RGD-Cy5-SS-Q was actively internalized by tumor cells and produced a much stronger fluorescence signal in tumor cells or in the stroma than RAFT-RGD-Cy5. This study also suggested that RAFT-RGD-Cy5-SS-Q bound to endothelial cells.

To demonstrate that RAFT-RGD could also target deep metastasis, similar studies were conducted in which RAFT-RGD-Alexa700 was intravenously injected in mice bearing intraperitoneal, luciferase-positive breast cancer nodules (obtained after intraperitoneal injection of TS/A-pc-pGL3 cells). Bioluminescence imaging was used to visualize scattered metastasis in the peritoneal cavity. Three hours after intravenous injection of RAFTRGDAlexa700, the binding on the tumor nodules was confirmed by 2D-FRI. This was more precisely evaluated using the fDOT system, as shown in Fig. 3. As expected, the metastases were not detectable using the negative control molecule RAFT-RAD-Alexa700, which do not bind the integrin.

The RAFT-RGD molecule is thus capable of targeting the cell surface receptor and inducing an active internalization in clathrin-coated vesicles (Sancey et al., 2009). To demonstrate that the RAFT-RGD vector can deliver an active toxic peptide in the appropriated subcellular compartment, we synthesized various "smart" molecules containing internally quenched FRET probes surrounding a cleavable disulfide link. In the first molecule, the FRET pair was made of $\mathrm{Cy} 3$ and $\mathrm{Cy} 5$. In the second molecule, $\mathrm{Cy} 3$ was replaced with a fluorescence quencher QSY21® as shown previously. In both cases, the disulfide bridge can be cleaved after reduction, which occurs during the internalization process. The use of $\mathrm{Cy} 3$ instead of QSY21®allowed us to simultaneously track each molecule separated after disruption of the 
disulfide bridge. Cy3 will stay attached to the RAFT-delivery vector while Cy5 will stay with the drug (KLA) (Fig. 1). This KLA peptide is toxic only when in contact with the mitochondria. It is thus necessary for the delivery system to release it in an active form into the cytoplasm of the cell after endocytosis. Only then can KLA reach the mitochondrion and destabilize it, leading to cell apoptosis.

Using RAFT-RGD-X1, we followed the targeting and release of KLA on $\square \mathrm{v} \square$ 3-expressing cells. As demonstrated in Fig. 4, the pseudo-colored "green" signal obtained by the Cy3 linked to the RAFT-RGD part was mainly localized at cell junctions but was also found in small vesicles, as previously described for RAFT-RGD alone (Sancey et a1., 2009). Most of the KLA, pseudo-colored in "red" was in the close vicinity of the vector RAFT-RGD or detached into the medium near the cell membranes. During the first half-hour, the FRET signal was weak, principally found at cell junctions and in some large speckles (upper panels). A weak FRET signal is the expected signature obtained when the two dyes are separated after degradation of the disulfide bridge during internalization. After $2 \mathrm{~h}$, KLA was mostly internalized but a large amount was still linked to the RAFT-RGDvector: a positive FRET signal was found in subcellular organelles such as the nucleus. Usually, RAFT-RGD stayed onthe cell membrane or was internalized in small clathrin-coated vesicles, but it was never observed in the nucleus (Sancey et al., 2009). This suggests that after partial release of the KLA toxic peptide, the nuclear membrane may be more permeable or that addition of KLA onto the RAFT-RGD could provide an NLS-like property to the molecule. FRET intensity was stronger at $\mathrm{T}=2 \mathrm{~h}$ than at $\mathrm{T}=30 \mathrm{~min}$ butthe $\mathrm{Cy} 3$ signal decreased during the same period: this indicated that the release of the KLA decreased with time, while the accumulation of the intact molecule was still ongoing. 


\subsection{Drug release}

Drug release could be observed with the RAFT-RGD-X2 (Fig. 5). Depending on the cell type, the time of release varied, but in three different cell types, the red signal resulting from KLA release was observed first in small vesicles (Fig. 5A) and then around the mitochondria (Fig. 5B) and labeled with the mito-tracker (green). This experiment demonstrated the efficiency of RAFT-RGD to carry and deliver this drug into three different cell types.

\subsection{Optical imaging for in vivo study of the biodistribution of nanoparticles}

Whole-body 2D-FRI can be used to compare the distribution of various surface modified nanoparticles $24 \mathrm{~h}$ after intravenous injection (Fig. 6). As demonstrated in Fig. 6 (A) and (C), these nanoparticles present distinct biodistributions (see supplementary data S2 and S3). In one case (Fig. 6A), the biodistribution seemed to be homogenous with a predominant hepatic elimination route. In the second case (Fig. 6C), the kidneys were highly fluorescent. Semiquantification of fluorescence intensities of the corresponding isolated organs (Fig. 6B and D) was correlated with whole-body noninvasive imaging.

Biodistribution quantification estimated the circulation timesin mice as well as the routes and time of elimination. In the first case (Fig. 6 A-B), we observed a long-lasting hepatic fluorescence signal $24 \mathrm{~h}$ after injection. Indeed, the massive accumulation of fluorescence in the liver and the significant level of fluorescence in the intestine indicated that these nanoparticles were probably degraded and excreted through feces. This elimination mode is slower than the urinary route, increasing the circulation time of the compound in the mouse, thus favoring specific targeting or passive uptake. In the second case presented (Fig. 6 C-D), nanoparticles freely circulated in the blood and were quickly cleared from the body through the kidneys; no fluorescence was detected except in this organ. It is therefore likely that these 
nanoparticles were degraded and the fluorescence released and eliminated through the urinary route. The integrity of the nanoparticles in the different compartments is difficult to control. To address this problem, we are currently working on the introduction of a FRET system instead of a single dye. This should help determine whether the particle is still intact at the end.

Moreover, whole-body scans and quantifications allowed us to evaluate the tumoral uptake. For one of the two nanoparticles (Fig. 6 A-B), we observed a weak accumulation in the tumor due to passive and nonspecific targeting.

As demonstrated by Frangioni and Mawad's teams (Kim et al., 2004; Sevick-Muraca et al., 2008), such nanoparticles have the capacity to accumulate passively in draining lymph nodes. This is an interesting application since it may help identify draining lymph nodes associated with tumors. We therefore injected untargeted nanoparticles in two peri-tumoral locations (pink dots) and used the Fluobeam imaging system to follow the distribution of the nanoparticles in real time, as shown in Fig. 7, $15 \mathrm{~min}, 1 \mathrm{~h}$ and $3 \mathrm{~h}$ after injection. As observed after $3 \mathrm{~h}$, two lymph nodes were identified draining directly the subcutaneous tumor. The advantage of using the Fluobeam instead of the conventional 2D-FRI system is its ability to function under surgical white light, allowing us to detect and remove such draining lymph node by optical-guided surgery (see supplementary data $\mathrm{S} 4$ ). This could be done as well in large animals (pigs, goat...) because the Fluobeam does not require the introduction of the animal in a black box, oppositely to all other conventional fluorescent imaging systems.

\section{Discussion}

In this study, we illustrated how optical imaging can help in the development of targeted therapeutics in oncology. This method allows us to noninvasively follow the fate of a 
molecule and its functional activation on a very broad scale. Indeed, using a fluorescent tag, the distribution of the desired molecule can be followed from the subcellular level up to the whole-body level (Pierce et al., 2008).

For cell targeting and drug release, we used a synthetic peptidic RAFT-RGD vector targeting the $\square \mathrm{v} \square$ integrin. Combined with different fluorescent or smart-FRET probes, we studied its efficiency in delivering and releasing a toxic peptide, normally unable to cross the cell membrane on its own.

The FRET experiment demonstrated a rapid release of the drug after disulfide bridge rupture occurring after its internalization mediated by the RAFT-RGD vector in small endocytic and acidic vesicles (Sancey et al., 2009). After 2 h, the drug perforated many organelles, leading to cell death and allowing the compound to penetrate the nucleus. In this analysis, the different pictures were obtained after 543-or 633-nm laser excitations, for the Cy3 and FRET or Cy5 channel, respectively. Furthermore, the intensity of the 543-nm laser differed between Cy3 and FRET analysis. The use of different lasers and intensities prevented us from comparing the fluorescence intensities of the different emission channels. Here, two phenomena were observed: RAFT-RGD-X1 accumulation and KLA release. As we could not quantify each phenomenon separately, the amount of drug released could not be quantified in this experiment.

The RAFT-RGD-X2 was constructed to follow the release of the drug and its intracellular trafficking. The time course of drug release varied with the cell type. In the three different cell types, red vesicles first appeared before accumulation in the mitochondrion. Since small quantities of RAFT-RGD-X2 in solution ( $2 \square \mathrm{M}$ ) were used, we assumed that only a small quantity of the drug combined with the Cy5 was internalized with the vector RAFT-RGD, released into small vesicles, and escaped this organelle. This small proportion of released 
drug reached its target, as demonstrated by its colocalization with the mito-tracker probe. This proportion was sufficient to induce substantial cell damage representative of cell death: as demonstrated in Fig. 4, this concentration induced perforations of the nuclear membrane, leading to the diffusion of the vector and its drug into this organelle. Furthermore, the KLA also perforated the mitochondrial membranesdisturbing their polarization and leading to cell death (data not shown).

Such functional characteristics could effectively be investigated with optical imaging techniques. This method gives access to in celluloassociation/dissociation of compounds using appropriate techniques (FRET, FRAP, etc) (Rajwa, 2005). At the animal level, optical imaging also allowed us to determine specific organ accumulation, particularly in tumors, and gave functional information such as tumoral growth and vascularization (Weissleder and Pittet, 2008).

Using innovative nano-carriers, we studied their elimination route and biodistribution features after PEGylation of their surface. Nano-carriers should be accurately targeted to obtain an acceptable biodistribution without accumulating in vital organs. The biodistribution depends on several physicochemical properties of the nano-carriers such as their size, but also the electrostatic charge and chemical composition of their surface (Debbage and Jaschke, 2008). Since fluorescence optical imaging is an easy, immediate, and noninvasive method, this tool makes a major contribution to the development of new innovative antitumoral nano-carriers (Weissleder, 2002; Weissleder and Pittet, 2008).

We can use fluorescent dyes that are excitable at wavelengths greater than or equal to $633 \mathrm{~nm}$ at least, in particular for animal investigations. Imaging in the NIR spectrum (650-900nm) maximizes tissue penetration in addition to minimizing the autofluorescence from nontargeted tissues (Weissleder, 2001; Weissleder and Ntziachristos, 2003). The signal-to-background 
ratio, for detecting optical imaging agents, equals or exceeds that which can be achieved with other molecular imaging modalities.

One of the major drawbacks of optical imaging concerns its limited depth of investigation. Depending on the machine used, the emission signal was collected at a $15-\mathrm{cm}$ depthat best (Frangioni, 2008). The development of 3D cameras allows whole-body noninvasive investigations on small animals such as mice and rats. At the clinical level, optical imaging could be used to facilitate the surgery using nanoparticle probes, for example as established here for lymph node detection using a surgical Fluobeam device, or for other applications (Frangioni, 2008; Jechart and Messmann, 2008).

Optical imaging is a sensitive method: 2 pmol of fluorescent Cy5 could be detected in the mouse brain (V. Josserand, unpublished data), a good spatial resolution close to the millimeter in $3 \mathrm{D}$ and $0.01 \mathrm{~mm} 2$ in 2D (Collier et a1., 2007; Frangioni, 2008), anda very fast temporal resolution. For example, in 2D, a series of images can be taken with milliseconds of exposure time. It must be noted that a 3D acquisition of a $2-\mathrm{cm}_{3}$ volume is slower and would require 10-15 min.

To conclude, optical imaging is an inexpensive, easy-to-use, and nonradiative tool able to provide rapid semi-qualitative (2D), quantitative (3D), and functional information from cellular to the several-centimeter scale.

\section{Acknowledgements}

This study was supported by the Institut National de la Santé et de la Recherche Médicale (INSERM), the INCA (Institut National pour le Cancer), the Association for Researchon 
Cancer (ARC, France), the Agence Nationale pour la Recherche (ANR) and the EMIL and N2L NoE of the 6th FWP. We also acknowledged Stéphanie Guillermet (Fluoptics, Grenoble France) and Alexeï Grichine (CRI/INSERM U823, Eq. 10) for helpful technical assistance. 


\section{Figure legends}

Fig. 1: Representation of the RAFT-RGD drug carrier. The disulfide bridge is represented by "S-S". Here, the drug is the pro-apoptotic (KLAKLAK)-NH2peptide.

Fig. 2: Schematic representation of functionalized nanoparticles for imaging and targeted therapies.

Fig. 3: Optical imaging of intraperitoneal TS/A-pc-pGL3 tumor-bearing mice. The tumor cells were detected noninvasively using different modalities and the positive RAFT-RGDAlexa700 molecule (Left) or the negative control molecule RAFT-RAD-Alexa700 (Right). Bioluminescence imaging, 5 min after luciferase injection allowed the detection and localization of the peritenoal nodules because the injected tumor cells are Luciferase positive. 2D-fluorescence and 3D fluorescence imaging performed $3 \mathrm{~h}$ after intravenous injection of RAFT-RGD-Alexa700 and RAFT-RAD-Alexa700demonstrated that RAFT-RGD but not RAFT-RAD was targeting these nodules.

Fig. 4: Confocal imaging of RAFT-RGD-X1 on live $\square \mathrm{v} \square$ 3-expressing cells, HEK293- $\square$ 3. From left to right: phase contrast and nucleus staining (blue), RAFT-RGD-Cy3 (green), KLA-Cy5 (red), and FRET signal obtained from KLA linked to RAFT-RGD (dark red). The images were obtained at $30 \mathrm{~min}$ (upper panel) and $2 \mathrm{~h}$ (lower panel). Scale bar: $20 \square \mathrm{m}$.

Fig. 5: Drug release. (A) IGROV-1 cellswere incubated with RAFT-RGD-X2 and observed by confocal microscopy (40x). Red signal corresponding to the drug release appeared $1 \mathrm{~h}$ 
after addition to the cell culture medium. As demonstrated by the mitochondria labeling (green signal), the KLA massively reached its target. (B) Similar results were obtained on three different cell types expressing the integrin $\alpha_{v} \beta_{3}$. Scale bar: $10 \square \mathrm{m}$.

Fig. 6: (A)and (C)Fluorescence reflectance imaging of nudemice laid on the back (left) and the belly (right), $24 \mathrm{~h}$ after the intravenous injection of two different nanoparticles (representative examples, $\mathrm{N}=4$ ). (B)and (D)Corresponding biodistributionsof the different nano-carriers were obtained after sacrifice of the animals and exposure of the different organs directly under the camera.

Fig. 7: Nanoparticles were subcutaneously injected in two locations in the vicinity of the tumor (pink dots). As observed after $15 \min (A), 1 \mathrm{~h}(\mathrm{~B})$ or $3 \mathrm{~h}(\mathrm{C})$, the nanoparticles were migrating toward two draining lymph nodes of the subcutaneous tumor, allowing their precise localization. (D) After resection, lymph nodes were observed under bright field and fluorescence imaging. 


\section{References}

Ahmadi, M., Sancey, L., Briat, A., Riou, L., Boturyn, D., Dumy, P., Fagret, D., Ghezzi, C.Vuillez, J.P., 2008. Chemical and Biological Evaluations of an 111In-Labeled RGDPeptide Targeting Integrin $\square \mathrm{v} \square 3$ in a Preclinical Tumor Model. Cancer Biother. Radiopharm. 23, 1-10

Anandasabapathy, S. 2008. Endoscopic imaging: emerging optical techniques for the detection of colorectal neoplasia. Curr. Opin. Gastroenterol. 24, 64-69.

Alexis, F., Pridgen, E., Molnar, L.K., Farokhzad, O.C., 2008. Factors affecting the clearance and biodistribution of polymeric nanoparticles. Mol. Pharm.5, 505-515.

Boturyn, D., Coll, J.L., Garanger, E., Favrot, MC., Dumy, P., 2004. Template assembled cyclopeptides as multimeric system for integrin targeting and endocytosis. J. Am. Chem. Soc. $126,5730-5739$.

Bridot, J.L., Faure, A.C., Laurent, S., Rivière, C, Billotey, C., Hiba, B., Janier, M., Josserand, V., Coll, J.L., Elst, L.V., Muller, R., Roux, S., Perriat, P., Tillement, O., 2007. Hybrid gadolinium oxide nanoparticles: Multimodal contrast agents for in vivo imaging. J. Am. Chem. Soc.129, 5076-5084.

Chen, X., Sievers, E., Hou, Y., Park, R., Tohme, M., Bart, R., Bremner, R., Bading, J.R., Conti, P.S., 2005. Integrin alpha v beta 3-targeted imaging of lung cancer. Neoplasia 7, 271-279.

Cho, K., Wang, X., Nie, S., Chen, Z.G., Shin, D.M., 2008. Therapeutic nanoparticles for drug delivery in cancer. Clin. Cancer Res. 14, 1310-1316.

Clift, M.J., Rothen-Rutishauser, B., Brown, D.M., Duffin, R., Donaldson, K., Proudfoot, L., Guy, K., Stone, V., 2008. The impact of different nanoparticle surface chemistry and 
size on uptake and toxicity in a murine macrophage cell line. Toxicol. Appl.

Pharmacol.232, 418-427.

Collier, T., Guillaud, M., Follen, M., Malpica, A., Richards-Kortum, R., 2007. Real-time

reflectance confocal microscopy: comparison of two-dimensional images and three-

dimensional image stacks for detection of cervical precancer. J. Biomed. Opt. 12, 024021.

Da Silva, A., Dinten, J.M., Coll, J.L., Rizo, P., 2007. From bench-top small animal diffuse optical tomography towards clinical imaging. Conf. Proc. IEEE Eng. Med. Biol. Soc. 2007, 526-529.

Debbage, P., Jaschke, W., 2008. Molecular imaging with nanoparticles: giant roles for dwarf actors. Histochem.Cell Biol. 130, 845-875.

Foillard, S., Jin, Z.H., Garanger, E., Boturyn, D., Favrot, M.C., Coll, J.L., Dumy, P., 2008.

Synthesis and biological characterisation of targeted pro-apoptotic peptide. Chem.

Bio. Chem.9, 2326-2332.

Frangioni, J.V., 2008. New technologies for human cancer imaging. J. Clin. Oncol. 26, $4012-$ 4021.

Garanger, E., Boturyn, D.Dumy, P., 2007. Tumor targeting with RGD peptide ligands-design of new molecular conjugates for imaging and therapy of cancers. Anticancer Agents Med.Chem. 7, 552-558.

Garanger, E., Boturyn, D., Jin, Z., Dumy, P., Favrot, M.C., Coll, J.L., 2005. New multifunctional molecular conjugate vector for targeting, imaging, and therapy of tumors. Mol. Ther. 12, 1168-1175.

Gehlsen, K.R., Davis, G.E.Sriramarao, P., 1992. Integrin expression in human melanoma cells with differing invasive and metastatic properties.Clin. Exp.Metastasis 10, 111-120. 
Gladson, C.L., Cheresh, D.A., 1991. Glioblastoma expression of vitronectin and the alpha v beta 3 integrin. Adhesion mechanism for transformed glial cells. J. Clin. Invest. 88, 1924-1932.

Herve, L., Koenig, A., Da Silva, A., Berger, M., Boutet, J., Dinten, J.M., Peltie, P., Rizo, P., 2007. Noncontact fluorescence diffuse optical tomography of heterogeneous media. Appl.Opt.46, 4896-4906.

Jechart, G., Messmann, H., 2008. Indications and techniques for lower intestinal endoscopy. Best Pract.Res.Clin. Gastroenterol.22, 777-788.

Jin, Z.H., Josserand, V., Foillard, S., Boturyn, D., Dumy, P., Favrot, M.C., Coll, J.L., 2007. In vivo optical imaging of integrin $\square \mathrm{v} \square$ 3in mice using multivalent or monovalent cRGD targeting vectors. Mol.Cancer 6, 41.

Jin, Z.H., Josserand, V., Razkin, J., Garanger, E., Boturyn, D., Favrot, M.C., Dumy, P., Coll, J.L., 2006. Noninvasive optical imaging of ovarian metastases using Cy5-labeled RAFT-c(-RGDfK-)4. Mol. Imaging5, 188-197.

Josserand, V., Texier-Nogues, I., Huber, P., Favrot, M.C.Coll, J.L., 2007. Non-invasive in vivo optical imaging of the lacZ and luc gene expression in mice. Gene Ther. 14, 1587-1593.

Kim, S., Lim, Y.T., Soltesz, E.G., De Grand, A.M., Lee, J., Nakayama, A., Parker, J.A., Mihaljevic, T., Laurence, R.G., Dor, D.M., Cohn, L.H., Bawendi, M.G., Frangioni, J.V., 2004. Near-infrared fluorescent type II quantum dots for sentinel lymph node mapping. Nat.Biotechnol.22, 93-97.

Koenig, A., Herve, L., Josserand, V., Berger, M., Boutet, J., Da Silva, A., Dinten, J. M., Peltie, P., Coll, J. L., Rizo, P., 2008. In vivo mice lung tumor follow-up with fluorescence diffuse optical tomography. J. Biomed. Opt. 13, 011008. 
Kumar, S., Richards-Kortum, R., 2006. Optical molecular imaging agents for cancer diagnostics and therapeutics. Nanomed.1, 23-30.

Luker, G. D., Luker, K. E. 2008. Optical imaging: current applications and future directions. J. Nucl. Med. 49, 1-4.

Lukyanov, A.N., Torchilin, V.P., 2004. Micelles from lipid derivatives of water-soluble polymers as delivery systems for poorly soluble drugs. Adv. Drug Deliv. Rev. 56, 1273-1289. Owens, D.E., 3rd, Peppas, N.A., 2006. Opsonization, biodistribution, and pharmacokinetics of polymeric nanoparticles. Int.J. Pharm.307, 93-102.

Pierce, M.C., Javier, D.J., Richards-Kortum, R., 2008. Optical contrast agents and imaging systems for detection and diagnosis of cancer. Int.J. Cancer.123, 1979-1990.

Rajwa, B., 2005. Modern confocal microscopy. Curr.Protoc.Cytom.Chapter 12, Unit 1213. Ripol1, J., Yessayan, D., Zacharakis. G., Ntziachristos, V., 2005. Experimental determination of photon propagation in highly absorbing and scattering media. J. Opt. Soc. Am. A. Opt. Image Sci. Vis. 22, 546-551.

Rolli, M., Fransvea, E., Pilch, J., Saven, A., Felding-Habermann, B., 2003. Activated integrin alphavbeta3 cooperates with metalloproteinase MMP-9 in regulating migration of metastatic breast cancer cells. Proc.Natl.Acad.Sci. U S A 100, 9482-9487. Rupp, P.A., Czirok, A., Little, C.D., 2004. alphavbeta3 integrin-dependent endothelial cell dynamics in vivo. Development 131, 2887-2897.

Sancey, L., Ardisson, V., Riou, L.M., Ahmadi, M., Marti-Batlle, D., Boturyn, D., Dumy, P., Fagret, D., Ghezzi, C., Vuillez, J.P., 2007. In vivo imaging of tumour angiogenesis in mice with the $\square_{\mathrm{v}} \square_{3}$ integrin-targeted tracer 99mTc-RAFT-RGD. Eur. J. Nucl. Med. Mol. Imaging. 34, 2037-2047.

Sancey, L., Garanger, E., Foillard, S., Schoehn, G., Hurbin, A., Albigès-Rizo, C., Boturyn, D., 
Souchier, C., Grichine, A., Dumy, P., Coll, J.L., 2009. Clustering and internalization of integrin $\square \mathrm{v} \square 3$ with a tetrameric RGD-synthetic peptide. Mol. Ther. in press.

Sato, T., Konishi, K., Kimura, H., Maeda, K., Yabushita, K., Tsuji, M., Miwa, A., 2001.

Vascular integrin beta 3 and its relation to pulmonary metastasis of colorectal carcinoma. Anticancer Res.21, 643-647.

Seftor, R.E., Seftor, E.A., Gehlsen, K.R., Stetler-Stevenson, W.G., Brown, P.D., Ruoslahti, E., Hendrix, M.J., 1992. Role of the alpha $\mathrm{v}$ beta 3 integrin in human melanoma cell invasion. Proc.Natl.Acad.Sci. U S A 89, 1557-1561.

Sevick-Muraca, E.M., Sharma, R., Rasmussen, J.C., Marshall, M.V., Wendt, J.A., Pham, H.Q., Bonefas, E., Houston, J.P., Sampath, L., Adams, K.E., Blanchard, D.K., Fisher, R.E., Chiang, S.B., Elledge, R., Mawad, M.E., 2008. Imaging of lymph flow in breast cancer patients after microdose administration of a near-infrared fluorophore: feasibility study. Radiology 246, 734-741.

Stupack, D.G., Cheresh, D.A., 2002. Get a ligand, get a life: integrins, signaling and cell survival. J. Cell Sci.115, 3729-3738.

Tromberg, B. J., Cerussi, A., Shah, N., Compton, M., Durkin, A., Hsiang, D., Butler, J., Mehta, R. 2005. Imaging in breast cancer: diffuse optics in breast cancer: detecting tumors in pre-menopausal women and monitoring neoadjuvant chemotherapy. 7, 279-285. Weissleder, R., 2001. A clearer vision for in vivo imaging. Nat.Biotechnol. 19, 316-317. Weissleder, R., 2002. Scaling down imaging: molecular mapping of cancer in mice. Nat. Rev. Cancer 2, 11-18.

Weissleder, R., Ntziachristos, V., 2003. Shedding light onto live molecular targets. Nat. Med. 9, 123-128.

Weissleder, R., Pittet, M.J., 2008. Imaging in the era of molecular oncology. Nature452, 580-589. 

Figure 1

QuickTime $^{T M}$ et un

décompresseur

sont requis pour visionner cette image. 
Figure 2

QuickTime ${ }^{T M}$ et un

décompresseur sont requis pour visionner cette image. 
Figure 3

QuickTime $^{\mathrm{TM}}$ et un

décompresseur

sont requis pour visionner cette image. 
Figure 4

$$
\begin{aligned}
& \text { QuickTime }{ }^{T M} \text { et un } \\
& \text { décompresseur }
\end{aligned}
$$

sont requis pour visionner cette image. 
Figure 5

QuickTime $^{T M}$ et un

décompresseur
sont requis pour visionner cette image. 
Figure 6

QuickTime $^{\mathrm{TM}}$ et un
décompresseur

sont requis pour visionner cette image. 
Figure 7

QuickTime $^{T M}$ et un

décompresseur

sont requis pour visionner cette image. 